\title{
CITOLOGÍAS CÉRVICO VAGINALES PROCESADAS EN MEDIO LÍQUIDO Comparación con las convencionales
}

Juan Pablo Blanco, Jhon Mauricio Franco, Ignacio Hernández, Alexander Juyo.*

\section{Resumen}

Objetivo: evaluar la calidad de la muestra procesada en medio líquido en comparación al método convencional.

Métodos: se realizó un análisis observacional descriptivo en el cual fueron estudiadas 32 citologías cérvico vaginales (CCV) de pacientes que acudieron a la campaña realizada en la institución Fundafidro, el día 24 de Junio del año 2003; se procesaron las muestras de manera convencional, los cepillos y espátulas utilizadas para la toma se llevaron al medio líquido para obtener 32 muestras adicionales, las cuales se procesaron en doble lámina, cada una con un botón celular obtenido por medio del Cytospin del Instituto Nacional de Cancerología (INC).

Resultados: se tomaron $40 \mathrm{CCV}$ de las cuales 32 cumplieron con los criterios de inclusión, en las cuales se realizó el citodiagnóstico de manera independiente para cada una de las técnicas.

Conclusiones: se demuestra que el método citológico en medio líquido mejora la calidad de la muestra, pero está limitado a los resultados que se obtienen al procesar la muestra sobrante del extendido. Se plantea la necesidad de realizar estudios complementarios que pongan en práctica las correcciones descritas.

Palabras Clave: citología cervicovaginal, método convencional, calidad de la muestra, procesamiento de muestras.

\section{Introduccilón}

La citología (CCV) la desarrolló Papanicolaou (PAP) en 1936 y en el mundo se empezó a difundir en la década de los 60. Desde que se implantó en nuestro país, se reconoce como un excelente medio de tamización para prevenir y detectar lesiones pre o cancerígenas.

Durante este tiempo se ha notado una reducción del índice de mortalidad por cáncer de cuello uterino en cerca del $70 \%$, pero aún así se registra como la segunda causa de muerte en nuestro país, con una tasa de mortalidad de 6.49 por 100.000 (según estadísticas recientes del INC.

El factor más importante que interviene en este umbral se refiere a la dificultad para la evaluación y diagnóstico de gran parte de la población, que nunca se ha tamizado

Estudiantes de último semestre Facultad de Citohistotecnología

** Este trabajo fue realizado bajo la tutoría de la Dra. Margarita Ruiz, Patóloga y Profesora Asociada de la Fundación Universitaria de Ciencias de la Salud, y de la Dra.Luddy Martín Bacci, Jefe del Depto. de Patología del Hospital de Kennedy. y por lo regular son grupos de alto riesgo; además otro factor importante es la deficiente calidad de la muestra.

Pensando siempre en mejorar la calidad del procedimiento (recolección, extensión, fijación, tinción y evaluación citológica) y contemplando el aumento de diagnósticos falsos negativos que varían entre el 3 y $30 \%$, y de los cuales cerca del $90 \%$ se deben a limitaciones y deficiencias de la calidad de la muestra, el grupo investigador se propuso realizar un procedimiento de recolección y procesamiento del material cervicovaginal, que permitiera disminuir los factores que comprometen la calidad, según los parámetros establecidos por el sistema Bethesda 1991.

A pesar de los inconvenientes y limitantes, el método de la CCV convencional ha permanecido inalterado por más de cinco décadas, gracias a los avances en la metodología de preparación de las muestras en los laboratorios de citopatología. La aversión al cambio se puede atribuir no sólo a la tendencia de ceñirse a la tradición, sino también a la escasa documentación de la nueva técnica en nuestro país. 


\section{Materiales y métodos}

Se realizó un análisis descriptivo de $32 \mathrm{CCV}$ de pacientes que asistieron a la campaña de promoción y prevención en la ciudad de Bogotá; se tomaron 40 citologías de las cuales se excluyeron 8 por ser pacientes embarazadas, vírgenes o con procedimientos quirúrgicos como histerectomía total o parcial. Las restantes cumplieron con las indicaciones y requerimientos para el estudio.

Los parámetros para evaluar la calidad de la muestra se rigieron según el sistema Bethesda 1991, por ser el más específico para este tipo de evaluación, clasificando las muestras como satisfactorias, satisfactorias pero limitadas e insatisfactorias de acuerdo con la cantidad y la calidad de sus componentes.

Obtenidas las 32 muestras en el fijador Cytospin Collection Fluid (CCF) se procesaron por centrifugación y decantación del sobrenadante, y el material restante se llevó a la cámara del Cytospin, de donde se obtuvo un botón celular por cada lámina, separando el material endocervical y exocervial en láminas independientes para cada paciente. Se analizaron un total de 64 láminas con el método en medio líquido y 32 con el convencional. Este trabajo se realizó en el laboratorio de citopatología del INC.

\section{Resultados}

Como norma, la técnica en medio líquido causa dispersión celular y algunas de las glandulares presentan cilias.

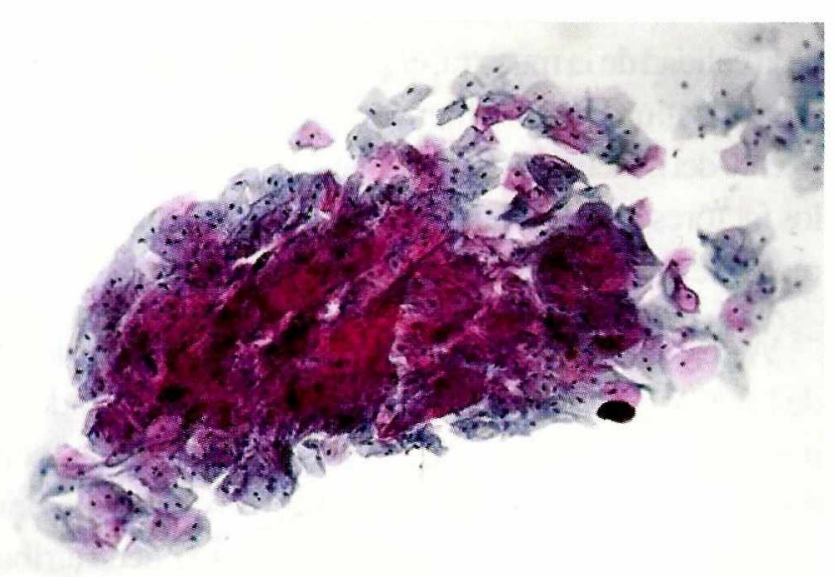

Figura I. Método convencional: grupo denso con sobreposición celular, difícil apreciación morfológica y artificios.
Los elementos de fondo como inflamación, hemorragia y moco desaparecen en forma total o significativa, apreciando un extendido más claro que permite identificar con fácilidad las características morfológicas de las células epiteliales, como son los núcleos, nucléolos, membranas nucleares y citoplasmáticas, al igual que la textura de la cromatina. Para la técnica en medio líquido se diagnosticaron 18 muestras como ssatisfactorias, 14 como limitadas, de las cuales 13 fueron por ausencia de material endocervical y 1 por inflamación que sobrepasó el $50 \%$ de la lámina.

\section{Discusión}

El propósito del estudio fue comparar la calidad de la muestra entre la CCV en medio líquido frente al con-

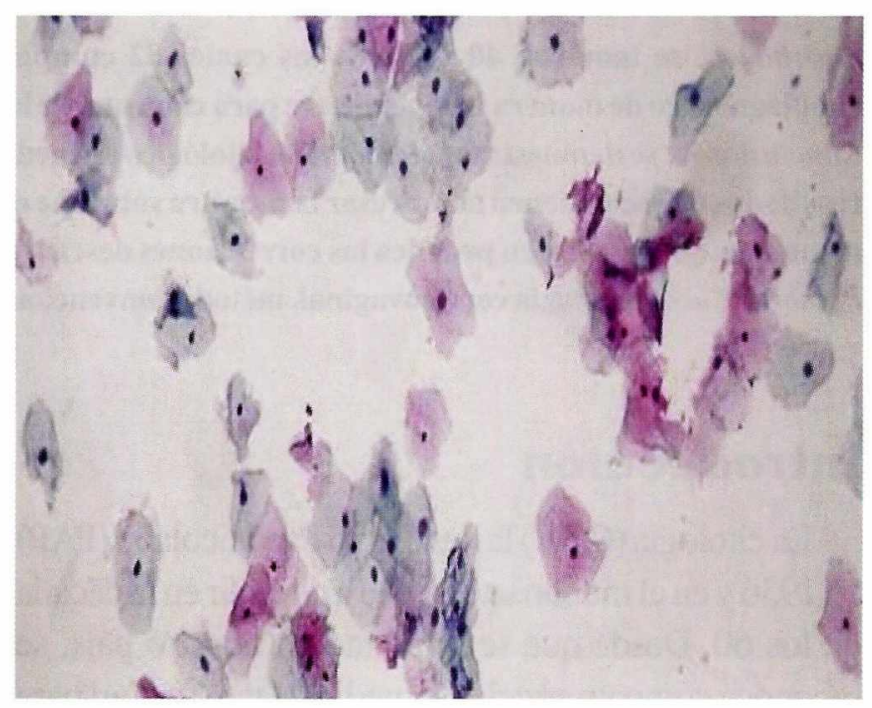

Figura 2. Método en medio líquido: densidad y dispersión celular de fácil apreciación morfológica.

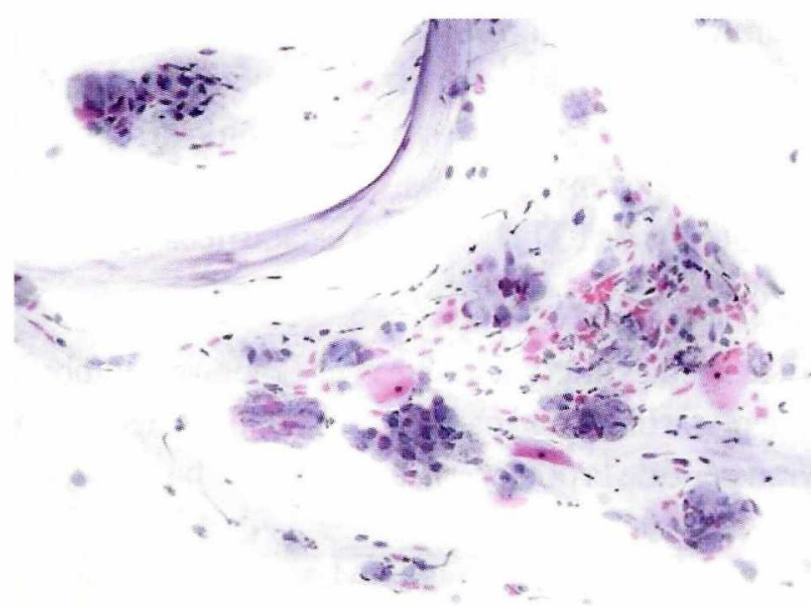

Figura 3. Método convencional: lagunas de moco, células endocervicales, hemorragia leve e inflamación moderada. 
vencional. Los resultados señalan que el primero es un proceso más sensible para asegurar la buena calidad de la muestra. Las pacientes que participaron en el estudio representaron una población diversa, incluyendo la de alto riesgo.

Para las muestras convencionales, la espátula de Ayre se extendió por ambas caras, el citocepillo se limpió haciendo giros horizontales sobre la lámina, para llevarla después a recipientes individuales con el líquido CCF usado para preservar las muestras. De esta manera el medio liquido queda en desventaja porque solo se aprovecha el material sobrante.

Las láminas en el medio líquido mostraron una distribución uniforme, con densidad celular en monocapa,

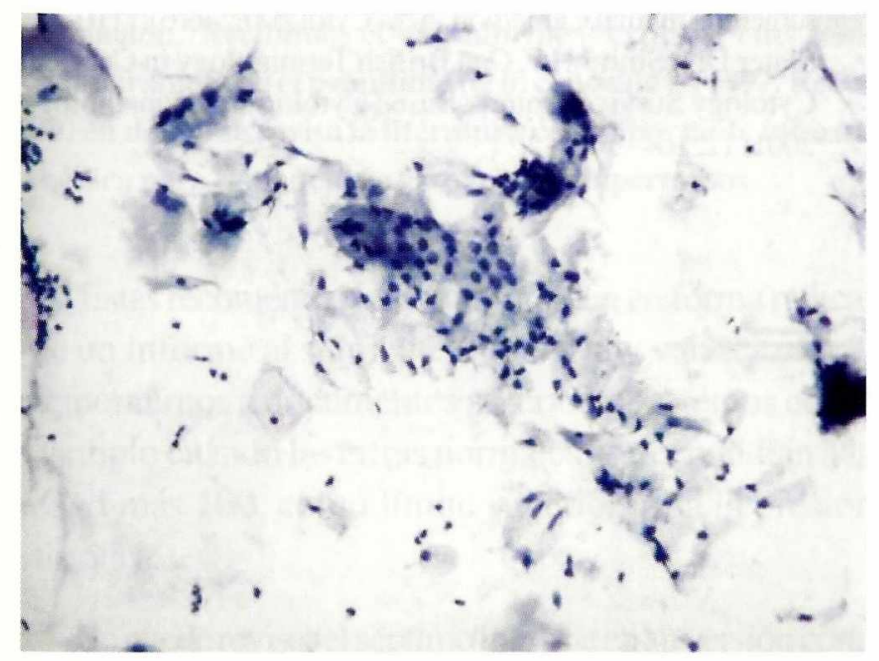

Figura 4. Método en líquido: células endocervicales libres de moco con presencia de cilias, lisis hemática e inflamación leve.

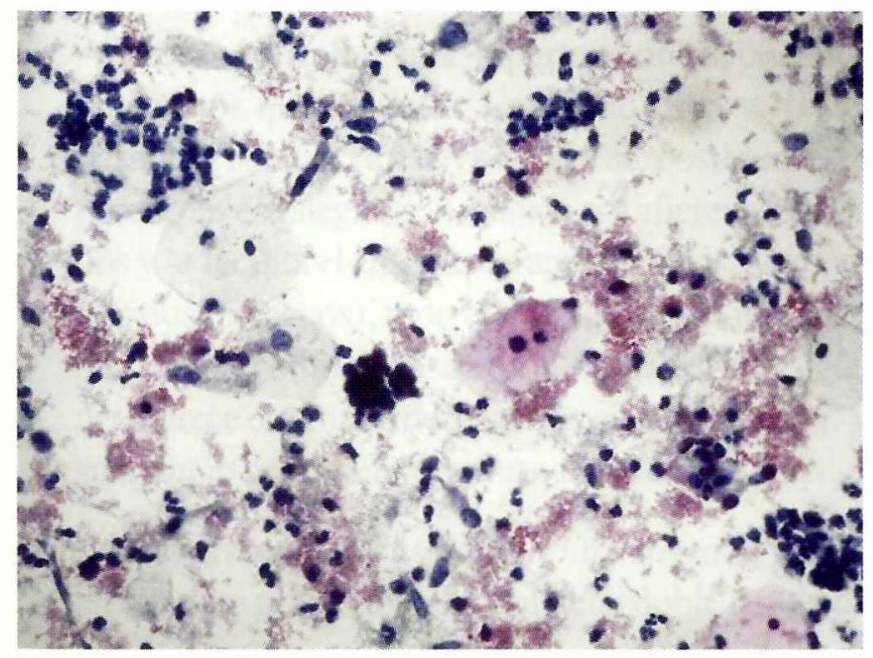

Figura 5. Método en medio líquido: lisis hemática, inflamación moderada y conservación morfológica. pérdida total o significativa de hemorragia, inflamación y moco, brindando así un fondo claro sin ocultar las células epiteliales.

De igual manera se evidenciaron en forma clara los cambios reactivos y los microorganismos, diagnosticados en dos círculos cada uno de $6 \mathrm{~mm}$ de diámetro, convirténdolo en una limitante por la escasa celularidad. Este parámetro fue establecido en el sistema Bethesda 1991. Además, se plantea la necesidad de evaluar si la pequeña cantidad de material es representativa de las células del cérvix. Para estudios futuros se recomienda procesar con cámaras de Citospyn de mayor capacidad en cuanto a volumen de muestra; de igual manera debe realizarse un estudio complementario procesando la muestra sobrante en bloque celular.

Las células endocervicales y metaplásicas se identificaron con medio líquido en 19, en comparación con 28 , mediante el método convencional. El proceso no demostró recuperación del material endocervical o por lo menos su equivalente, limitando 11 muestras por ausencia de células endocervicales, lo cual reitera la desventaja de trabajar con el material sobrante.

\section{Conclusiones}

Los resultados obtenidos no se pueden extrapolar a la población general por tratarse de una muestra reducida para la evaluación de atipias celulares; sin embargo, es válida para la valoración de la calidad.

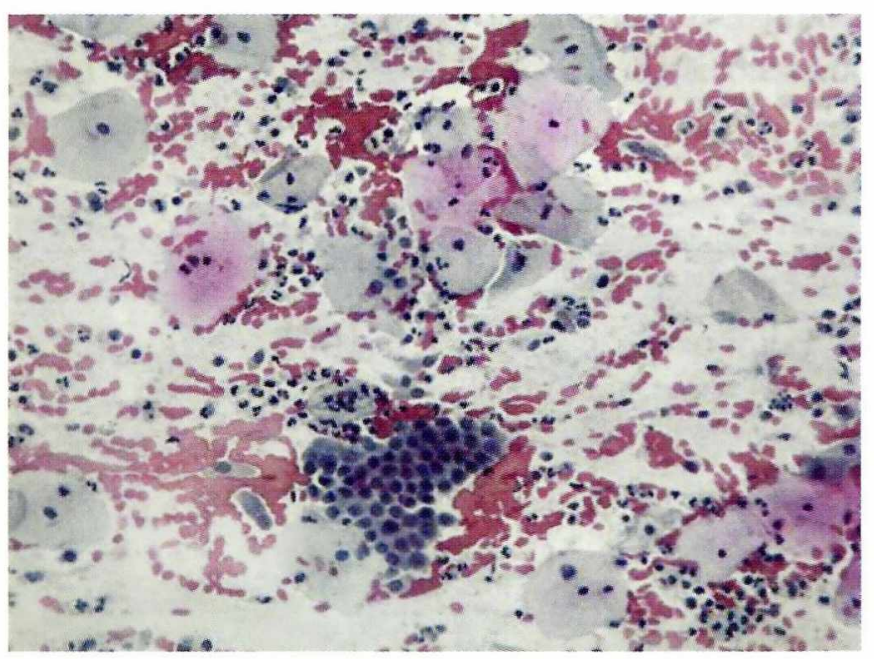

Figura 6. Método convencional: evidencia de células endocervicales sobre un fondo con hemorragia e inflamación severa. 
El procesamiento de CCV en medio líquido, aumenta costos y tiempo de realización, razón por lo cual presenta inconvenientes de adaptación como medio masivo de tamización.

En este orden de ideas, el uso de este método se debería limitar hacia aquellos casos especiales que requieren la mejor calidad posible por su dificultad diagnóstica.

Un estudio directo, es decir, tomar la muestra y llevarla al medio de recolección CCF, podría permitir que el 100\% del material exfoliado del cérvix se sometiera al procedimiento del medio líquido, lo cual daría un porcentaje similar al de las muestras que carecen de material endocervical en los extendidos convencionales.

\section{Lecturas recomendadas}

- Atkinson BF. Carbowax fixation of needle aspirates. Djagn Cytopathology 1986;2:231-32.
- Austin R, Marshall. Increased Detection of Detection of Epithelial Cell Abnormalities by Liquid.: Based Gynecologic. Acta Cytol 1998; 42(1): 178-83.

- Barbaraq F. Atkinson, Atlas de dificultades diagnosticas en citopatology 2000; 29.

- Belinson J L. Primary Screening whit Liquid Based Cytology In A Unscreened Population In Rural China, whit an emphasis on Reprocessing Unsatisfactory Samples. Acta cytol 2002; 46(3): 470 - 74.

- Hebert, J J. Personal view. Is it reality or an illusion that liquid - based cytology is better than conventional cytology? Citopathology 2001; 12: 383-89.

- Howel L P. The Autocyte Prerparation Sistem for Gynecologic Cytology, Acta Cytol 1998; 42 (1): 171-77.

- Kurman RJ, Salomon D.The Bethesda system for reporting cervical and Vaginal cytologic diagnoses. New York Verlag,1994.

- McGougan, E. Cell preparation Methods and Criteria for Sampt Adecuancy. Acta Cytol 11998; 42 (1):25-32.

- Rubir R. Feasibility of Citology - Based cervical cancer screening in ruial Cameroon. Acta Cytol 2002;46(6):1110-16.

- Slater DN, Smit J H F. Can British Terminology in Cervical Cytology Survive Liquid - Based Cytology? Cytopathology 2001; 12: 104-106

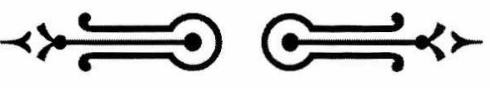

